\title{
POMPEII IN THE CRYSTAL PALACE : COMPARING VICTORIAN AND MODERN VIRTUAL, IMMERSIVE ENVIRONMENTS
}

Dr Nic Earle and Dr Shelley Hales

Education Support Unit \& Department of Classics and Ancient History

University of Bristol

Bristol

United Kingdom

nic.earle@bristol.ac.uk

shelley.hales@,bristol.ac.uk

http://sydenhamcrystalpalace.wordpress.com

\begin{abstract}
This JISC funded project involves building a virtual 3D model in Second Life, a multiuser online world, of the Pompeian Court, a life-size model of a Pompeian house built in the Crystal Palace in 1854. We wish to examine how the social and educational experiences and reconstructive possibilities offered by the virtual environment compare with those of the original Court. By examining these themes with reference to the archival material of the Palace and preliminary evaluation of our model with user groups in the education and heritage sectors, we aim to reassess the potential of visualisations of the past.
\end{abstract}

\section{INTRODUCTION}

This paper presents an overview of a project to build a virtual 3D model in Second Life, a popular multiuser online virtual world, of the Pompeian Court of the Crystal Palace. It is funded by JISC under the Enhancing Digital Collections strand of their Digitisation programme. The Court was a life-size model of a Pompeian house, housing a collection of copies of paintings from recent excavations. It was part of the Sydenham Crystal Palace, which opened in 1854 as a showcase of nineteenth century knowledge, an ambitious social and educational experiment, and which was destroyed by fire in 1936. We wish to examine how the social and educational experiences offered by the virtual environment of our Model compare with the successes and failures of the original Court. The questions of authenticity and of the responsibility of reconstructors raised by virtual visualisations, and also the issues of visitor behaviour and experience in an environment like Second Life, echo questions faced by the creators of the Pompeii Court. By examining these two aspects of the project with reference to historic data and to the results arising from preliminary evaluation of our project, we aim to begin to reassess the potential of visualisations of the past in the teaching of Arts \& Humanities.

\section{The Sydenham Crystal Palace}

After the Great Exhibition in Hyde Park, a group of private speculators, the Crystal Palace Company, bought the Crystal Palace, dismantled it and reassembled it on a larger scale in Sydenham in 1854. The Sydenham Palace, then, was itself already a 'copy', put 
EVA 2009 London Conference 6-8 July

Nic Earle and Shelley Hales

to new purpose but evoking the grand memory of the 1851 Exhibition. It was designed as a museum 'to educate, entertain and amuse', a tangible encyclopedia of the world. The main nave featured the Fine Arts Courts, a sequence of courts that showed the artistic and architectural achievements of past epochs, from Egypt to the Renaissance. Among these was the Pompeian Court, conceived as a replica of a Pompeian house which allowed visitors the chance literally to inhabit the Roman past. The most consistent and original feature of the Sydenham Palace was that throughout these exhibits, nothing was 'real', the Palace offered a world viewed at second remove, each exhibit manufactured using the latest techniques in iron, plaster and concrete [1].

\section{Objectives}

Our main objective is to build a 3D Model of the Pompeian Court that will act as an archive for the scattered literary and visual material documenting the Court and will visualise the knowledge we have of its contents, particularly its paintings. The choice to house this collection in a 3D visualisation rather than a database archive is dictated by our aim to interact with rather than simply present the Victorians' own attempt to visualise Pompeii. We wish to explore the worth of visualisation by mimicking, critiquing and comparing the aims of the past with today's technological innovations, museological attitudes and teaching and learning theories. If we are to increase access to this material, we must ensure that the Model is useful and engaging to a range of user groups across UK school and university education, research and heritage sectors.

\section{Evaluating Our Progress}

In order to meet these objectives, we have placed strong emphasis on alignment with the needs of our four key identified user groups. Following theories of user-centred development, we have designed the Model aware that user experience is affected by their own internal state, the context, and perceptions of the product [2]. At the outset of the project we identified existent needs that the Model could meet: it was designed to meet learning objectives of particular modules of the National Curriculum and to integrate with plans to develop the Crystal Palace Park. We have placed strong emphasis on consultation with our user groups throughout the project, not only better to understand needs and expectations, but to encourage engagement and ownership and promote dissemination. Before modelling began, we worked with focus groups including a class of Year 10 Classical Civilisation Students, a class of second year Classical Studies undergraduates from the University of Bristol, researchers from Bristol and London and local community heritage groups, the Crystal Palace Foundation and the Joseph Paxton Society. We explored what kind of information groups wanted to access, their expectations of visualisations and their attitudes to different media. Their responses fed into the development of the project plan, particularly in terms of the aspects of the Model we prioritised, and the design of learning activities and choice of methods of presenting meta- and paradata.

In June we begin a second phase of evaluation, in which user groups will work with the Model in a series of different environments: in structured learning activities in the class room at Bristol and Ipswich, in freer exploration and guided tours as part a 
EVA 2009 London Conference 6-8 July

Nic Earle and Shelley Hales

community arts festival on the Crystal Palace site during a community arts festival and an Open Day within Second Life itself. Data will be obtained from a variety of methods including observation, questionnaires and focus group discussions. With this data we hope to consider these particular questions. Do the educational/research benefits justify digitising archives in this way? Does the Model satisfy the needs of such a varied audience? Does the format inform users about the aims of the original Crystal Palace?

\section{TRUSTING VISUALISATIONS}

$3 \mathrm{D}$ visualisations have increasingly been used to recreate (in their imagined pristine conditions) buildings which are now either lost or in ruin. For example, students can visit the Parthenon and fly over ancient Rome from their PCs [3]. However, whilst enjoying these visualisations, it is often less clear how they might be most fruitfully embedded within teaching and learning and such issues are now becoming the focus of research [4]. Often preoccupied by the claims of veracity implied by virtual reality, users often see them as pass or fail exercises, that can either be validated or dismissed, an attitude that restricts the possibilities for further critical engagement. Our Model is based on an original (the Pompeian Court) that is completely lost but that was itself a model, based on a building (the House of the Tragic Poet) which, ironically, has become less of a ruin (by means of heavy reconstruction) since the nineteenth century. This complex history of models and prototypes mean that claims of and trust in authenticity and accuracy are necessarily questioned, encouraging our users to think about the links between the content of the Model and the mode of its delivery through visualisation in Second Life.

\section{Building the Crystal Palace}

Claims to authenticity were central to the Pompeian Court but its version of the past was, inevitably, subject to modern taste, opinions and practical necessity. Authenticity depended on its association with a real ruin, the House of the Tragic Poet, not because it was architecturally ideal but because it had become famous in a series of literary and artistic reconstructions, most famously Lytton's Last Days of Pompeii. That novel's description of the house assumed such authority that it featured in guides both to Pompeii and to the Pompeian Court. The Court diverged heavily from its model, having been made regular and symmetrical to fit the Palace's frame and Victorian taste. Few of the paintings were from the House of the Tragic Poet. Most of the wall schemes were created from disparate elements, taken from tracings made by Giuseppe Abbate from all over Pompeii. Although each element was 'accurate', the overall schemes were pastiche. Perhaps organisers felt free to reassemble them because, traditionally, Pompeian paintings were themselves seen as pastiches of lost Greek designs.

Nevertheless, the Court looked like a convincing whole. Reviews of the Palace show a marked preference for the Pompeian and Alhambra courts, the only two models of full buildings, suggesting that their immersive 'reality' was considered satisfying [5]. In fact, this immersive technique was fast becoming popular in exhibition circles: the Musée de Cluny had already arranged contemporaneous artefacts in themed rooms in order to allow visitors to 'walk in the midst of a vanished civilisation'. The Crystal 
EVA 2009 London Conference 6-8 July

Nic Earle and Shelley Hales

Palace Courts clearly influenced subsequent Expositions Universelles which featured copied buildings from distant lands. This innovative mode of exhibition, which Bann terms 'panoramic', reflected other emerging techniques of representation, such as the diorama [6]. The instructional capabilities of this mode were felt to be decisive: the Palace Company thought there was no better way to see a Pompeian house [7].

Just as the loss of materiality in online museums has caused anxiety, so did the strategies of the Crystal Palace: was it a museum when everything was fake? Was fakeness educational or just tacky? Full reconstruction inevitably accentuated its own artificiality. A French attack, dismissed the Court as a 'joujou', a 'plaything', an accusation which the entertainment focus of the Palace did little to counteract [8].

The Palace Company, however, was not emulating the traditional museums. Its members saw their endeavour as innovative and a direct challenge to elitist institutions, particularly the British Museum. Some of the Sydenham artefacts were copies of objects that could be seen 'in the flesh' in the British Museum, asking visitors to reflect on why they had chosen to see fakes in Sydenham and not the real thing in Bloomsbury.

\section{Authenticity}

In creating a visualisation of the Court, constructed in 3D Studio Max before migration into Second Life, we are able to draw on a number of sources, including the ground plan and textual information recorded in guidebooks and reviews, which offer clues to the decoration and the sources on which it was based. The Palace, a pioneer of reproductive techniques, was also documented by them: alongside lithographs, we have photographs, stereoscopes and daguerreotypes. We also use decorative designs taken from line drawings in published volumes, to which Abbate contributed, that advertised the findings of Pompeii across Europe [9]. In order to mimic the tracing process, we are making digital tracings of individual elements. Within the Model, the wall schemes are created from a combination of these sources, a pastiche of traced and photographed details. We work to the principles of the London Charter [10] in documenting our processes in full paradata. Strategies such as the juxtaposition of photographic primary sources and secondary traced elements embed this visually within the Model.

We have inevitably learned much about the decisions made by the 1854 designers. Like them we have made practical alterations - the Court was made bigger than its prototype for both ideological and practical reasons (to be 'worthy of empire' and to accommodate crowds) [11]. We have also had to increase the scale, since the social orientation of Second Life causes the size of avatars to be exaggerated. In teaching with the Model we constantly negotiate Victorian choices. Our school students wanted to know about Roman toilets only to find that Victorian sensibility had removed them. Such choices have further consequences: commentators often divided Pompeian houses into public, male and private, female parts along the lines of Greek homes, which were felt to be more morally acceptable than Roman ones. Taking the cue, artists and photographers documented the front, atrium, part of the house but gave only the skimpiest insight into the rear. Victorian opinions have physically and intellectually obscured aspects that today's historians have rightly or wrongly 'retrieved'. 


\section{EVA 2009 London Conference 6-8 July}

When first asked, all groups identified the accurate imitation of reality as the number one priority for a virtual model. But it was clear that what that reality was and why authenticity mattered differed between and among groups: particularly between those who felt they had a direct stake in the correct 'nuts and bolts' presentation of the Court (either through heritage or research concerns) and those more interested in atmosphere or concepts (mainly students but also other research and heritage group members) [12]. By having to deal with these issues (why you can't find the toilet in the Model that you can still see on a visit to the 'real' House of the Tragic Poet) the Model talks to users directly about the difficulties of returning to a pure past. Whilst one representative from the community heritage group expressed concern that children would find it difficult to grasp the intersection of Roman and Victorian history, it is a requirement of Key Stage 2 History that children become aware of the different ways in which History reaches them [13]. At a higher level, as teaching of the Humanities has increasingly turned to a reception-led model, Classics students are always aware that the fragments of the classical world are subject to constant re-editing, reproduction and rearrangement [14]. The experience of occupying the Model encourages users to consider the effects and ethics of reproduction and exhibition as a central part of their engagement with the past. Presenting Pompeii through this medium allows us to convey something of the ways of Pompeian life and of the ways in which successive audiences are able to imagine and create it. The aim of the learning activities in the Model will be to help students engage with visualisation both as a conceptual and manufactured process and as a finished, experienced product of Victorian or $21^{\text {st }}$ Century technology.

\section{ARTIFICIALITY}

Both the undergraduate and researcher groups expressed dissatisfaction with one aspect of virtual reality in particular: the 'edges' of a visualisation where, however convincing, the 'reality' is exposed as 'virtual', reveals itself to be a 'joujou'. Like all modellers, we have also faced this problem, considering the extent to which views from our Model will imitate those from the Court into the Palace nave. But, of course, the Court itself looked gloriously incoherent: its 'Pompeian' doors, windows and compluvium all gave way to views of the iron and glass modernity of the Palace superstructure. This dialogue was not hidden: the juxtaposition of Victorian technology and past aesthetics was a central tenet of the whole enterprise. Whilst this does necessarily make any easier our decision as to what to do with the edges of our SL space, it does make us and our visitors more critically aware of these issues.

The whole aura of Second Life helps us negotiate the boundary between authenticity and plaything. Like the Palace Court, our Model is in what is essentially a leisure environment. One of the appeals of Second Life to its market is that it includes relatively straightforward modelling tools that allow users to contribute to the built environment. Although, for the sake of migratability and back-up, we are importing the Model from 3D Studio Max, it adopts the format and modelling restrictions of the SL format. As a result, we cannot achieve photorealistic and atmospheric lighting effects of other forms of computer generated visualisation, such as those achieved in the video fly throughs of the Temple of Kalabsh [15]. Nevertheless, as well as overcoming practical 
obstacles like bandwidth limitations and the need for a computer with reasonable graphics capabilities, this does mean that something of the artificiality of the enterprise is conveyed to the SL user. Several participants in our school and undergraduate groups made comparison between the look of the environment and popular games like The Sims. This response evokes Gilly Salmon's work on teaching in Second Life as its role as 'edutainment', a label that might also be applied to the Crystal Palace and which we honour by adopting game theory in the design of our learning activities [16].

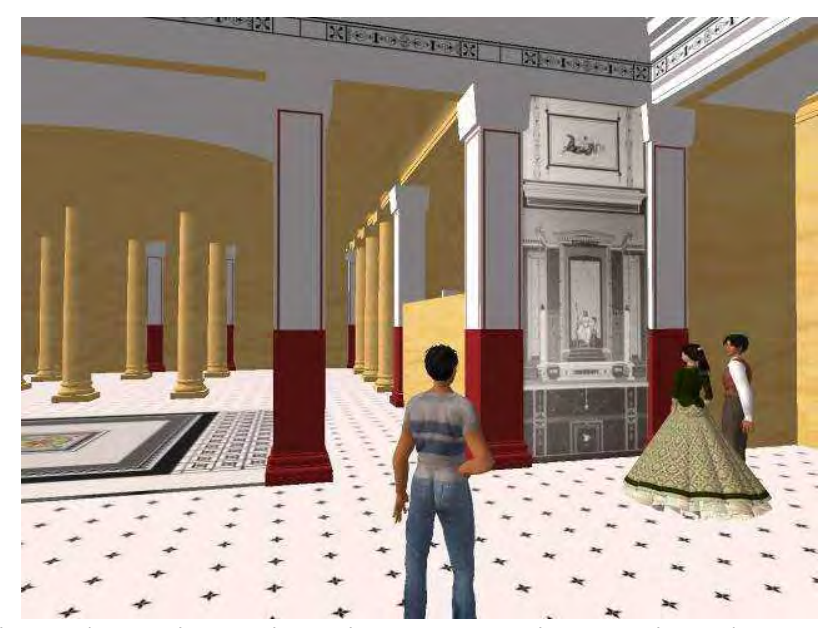

Figure 1. A visitor observing Victorian avatars inspecting the wall schemes in the model in progress

\section{VISITOR EXPERIENCE}

Both the undergraduate and school groups rated their own inhabitation of the model and interaction with the model, its exhibits and each other as the most desirable part of the project. These results concur with other projects into user experience of virtual reality that have stressed the importance of virtual presence over the imitation of reality [17]. Our project shifts focus onto exploring the experience of inhabiting these spaces (both as Pompeian house and Victorian exhibit) and instigating and observing social interaction. This involves negotiating tensions between what might be seen as two competing objectives: to emulate the environment and experience of visiting the Pompeian Court and to make the model useful and engaging to our user groups.

\section{Visitor Response in the Crystal Palace}

Given the stress laid by the Palace Company on the mission to educate the common man, an important part of understanding the success of the Court has to be how it catered for its different audiences, particularly how it balanced the needs of an upper class intelligentsia and the uneducated working classes. The guidebooks were supposed to deliver information for all. The guide to the Pompeian Court provided meta- and paradata, contextual information on Pompeii and Roman houses and insights into the workings of the project. Although over 80 pages long and almost entirely composed of dense text, it was purported to be written in 'easy' English and published separately, as 
EVA 2009 London Conference 6-8 July

Nic Earle and Shelley Hales

well with the other guides, in order to cater for every purse [18]. Beyond this there seems to have been little help. Photographic evidence reveals no labelling in the Court, so most visitors must have been unaware of what they were looking at. Satires which imagined working class caricatures recounting their garbled impressions of Palace sights imply that knowledge transfer was not terribly effective [19].

The gap between the enlightened and nonplussed will have exaggerated class differences. Anxiety about the behaviour of the working classes was a particular feature of the mid century and many press column inches were preoccupied with how they might or did behave in the Palace [20]. It was presumably the lack of explanation of the objects that turned visitors away from the Fine Arts Courts, which were a commercial disaster that had to be supplemented by money spinners such as firework displays and the FA Cup, aspects which were often seen as the triumph of lower class vulgarity.

Amidst this failure, the Pompeian Court seems to have retained its popularity, not because of its successful delivery of information but its imaginative and emotional associations. The popularity of Pompeii largely rested on the romantic impulse to travel back across time. The popularity of novels such as the Last Days of Pompeii played on this whilst a number of other Pompeian related stories dealt explicitly with the thrill of phantoms lurking in the ruins. The Pompeian Court afforded this immersive experience by proxy, encouraging fancies of encountering Pompeians (usually Lytton's characters) within it. Current research suggests that Pompeii's cataclysmic destruction attracted nineteenth century visitors because it served as a focus for the ontological crisis occasioned by modernity's savage breaks with the past [21]. As such, archaeological digs and reconstruction might be understood to have something in common with other attempts, as diverse as cinema and spiritualism, to materialise the intangible past.

\section{Access and Inclusion}

Our adoption of Second Life is central to the exploration of social behaviour and inclusion. This virtual environment is itself an ambitious social experiment, an ambivalent space in which the boundaries and hierarchies of Real Life might be brought into question. Interestingly, the most disenfranchised of our user groups, the Year 10 children, were most excited about adopting an avatar persona and interacting with others, whilst the researchers were most reluctant, irritated by being burdened by an avatar and being sidetracked by possible unwanted social interaction.

The researchers, however, and we, were interested in how the Model might replicate usage - how would visitors negotiate the space? We cannot make our viewers act as Victorians but we can use the range of reactions plotted by the Victorians as a means of assessing how people act in the light of social conventions of avatars. As the Model is permanently open, we could choose to 'turn off' the metadata to see how people navigate the space without help. We can offer authentic information through the digitised 1854 guidebook. We can also emulate the Victorian obsession with the souvenir: the Second Life snapshot sends greetings from the Victorian-Pompeian past.

More creatively, we can instigate clues to proper behaviour by the use of 'bot avatars in Victorian costume that will move around on predetermined paths, halting before key objects and perhaps reading aloud from the guidebook. We are particularly interested in 
EVA 2009 London Conference 6-8 July

Nic Earle and Shelley Hales

taking advantage of the latest research into avatars [22], particularly in the idea of giving them emotional reactions, programming bots to make gestures to each other that replicate the experiences of reviewers (a working class avatar showing deference to a gentleman, a woman conveying shock at the nude images). Another possibility is to allow visitors to adopt pre-configured avatars and to release only certain amount of information or access to particular figures. Role play scored particularly highly with the school students who wished to explore the house in Roman guise; a slave avatar, for example, might be excluded from a reception room. This kind of role play, as well as helping learn about the use of space, also helps articulate the experience of alienation or inclusion afforded to Roman and Victorian visitors of different social status and cultural awareness. By building these kind of structured learning activities into the Model we not only give it a clear purpose but also simultaneously draw attention to and overcome the limitations of engagement that did for the Crystal Palace.

Other possibilities, such as the delivery of information through audio as well as text means, the layering of quantities and depth of information, providing room for free exploration and guided tours, striking a balance between maintaining the academic integrity of the site whilst allowing visitors to contribute material and comment (a feature proposed by the Year 10 students) all help engage different audiences and increase access. They also begin to crowd a limited space and have to be managed so as not to impede on the experiences of others: a challenge on which we are now working.

\section{Ghostly Encounters}

Finally, Second Life is also a valuable format in which to emulate the interstitial space of Pompeii and the models, such as the Court, that drew on it. Across our focus groups, familiarity with Second Life was remarkably low: it was perceived as alien, though opinion divided on whether it was exotic or off-putting.

A recent EDUSERV project found that Second Life worked best as a teaching and learning medium, when the subject of the class played to the strengths of the environment [23]. This alien space appeared to help classes discuss topics relating to issues of social coherence and self-representation, topics made very real to participants through the adoption of an avatar and inhabitation of virtual space. Siân Baynes has further analysed the liberating and unnerving experience of learning in this environment [24]. By investigating the ontological shifts experienced by users as a meeting with the uncanny, her research begins to nod towards the kind of experiences had by Victorians in their attempts to reach Pompeii.

The limited number of 'bot avatars we aim to pilot over the summer further accentuate the sense of the uncanny in our project, particularly by developing 'bots that will interact with visitors. One possibility is that the division of these 'bots will exploit the shift between the front and back of the house. Whilst the atrium will house the Victorian 'bots replicating known visitor behaviour, in one of the rear rooms visitors will encounter a 'bot avatar in Roman dress who will be able to deliver information about Roman life. Yet again, the shifting authenticities and modes of the Model are accentuated by the medium of delivery in Second Life. 
EVA 2009 London Conference 6-8 July

Nic Earle and Shelley Hales

\section{CONCLUSION}

The preliminary results of our research suggest that the delivery of the Pompeian Court in Second Life fits the social and reproductive mechanisms that brought about its creation in 1854 and allows us to present the Pompeian house in its context of a long chain of material and scholarly and creative visualisations of the past. Our initial evaluation suggests that the possibility to demonstrate complex theoretical ideas about the reception of the past justifies digitising the Court in this way and that the visualisation is effective because both mode of delivery and content inform users about the aims of the Crystal Place as well as our own. The upcoming second phase of evaluation will tell us to what extent we have learned from the failures of the Crystal Palace to make a resource that can reach beyond the parameters of the project to its varied, target audiences.

\section{ACKNOWLEDGEMENTS}

We would like to thank JISC and Ben Showers, our programme manager, colleagues in the Education Support Unit and Department of Classics and Ancient History at Bristol and at KVL for their support, advice and encouragement.

\section{References}

[1] PIGGOT, J. The Palace of the People. London, 2004.

[2] VÄÄNÄNEN-VAINIO-MATTILA, K., ROTO, V. and HASSENZAHL, M. Towards practical user experience evaluation methods. In : Proceedings of the 5th COST294-MAUSE Open Workshop on Meaningful Measures : Valid Useful User Experience Measurement (VUUM 2008). 18th June, 2008, University of Iceland, Reykjavik, Iceland.

[3] http://earth.google.com/rome/

[4] THEATRON 3 Project. http://www.schome.ac.uk/ Building an interactive museum gallery in Second Life. http://www.archimuse.com/mw2008/papers/oberlander/oberlander.html

[5] HALES, S. Recasting antiquity in the Crystal Palace. Arion. 14, 2006. pp.99134.

[6] BANN, S. Views of the past. In : FYFE, G. and LAW, J. (eds) Picturing Power : visual depictions and social relations. London, 1988. pp.39-64.

[7] SCHARF, G. The Pompeian Court in the Crystal Palace. London, 1854. p.65.

[8] L'Illustration. January 1858. pp.7-10.

[9] Real Museo Borbonico. Naples 1824-57.

[10] BEACHAM, R., DENARD H. and NICCOLUCCI, F. An introduction to the London Charter. http://www.londoncharter.org/introduction.html

[11] SCHARF, G. The Pompeian Court in the Crystal Palace. London, 1854. p.27.

[12] LOWENTHAL, D. The heritage crusade and the spoils of history. Cambridge, 1998.

[13] National Curriculum. History Key Stage 2.

http://curriculum.qca.org.uk/key-stages-1-and-

2/subjects/history/keystage2/index.aspx 
EVA 2009 London Conference 6-8 July

Nic Earle and Shelley Hales

[14] MARTINDALE, C. and THOMAS, R. Classics and the uses of reception. Oxford, 2006.

[15] SUNDSTEDT, V. CHALMERS, A. and MARTINEZ, P. $\underline{A}$ high fidelity reconstruction of Ancient Egypt - the Temple of Kalabsha. ACM SIGGRAPH : Conference Abstracts and Applications. San Diego, USA July 2003

[16] DODSON, S. Is there a Second Life for teaching? The Guardian. http://www.guardian.co.uk/digitalstudent/second-life

[17] DI BLAS, N., GOBBO, E. and PAOLINI, P. 3D Worlds and cultural heritage : realism vs. virtual presence. In: TRANT, J. and BEARMAN, D. (eds.), Museums and the Web 2005 : Proceedings. Toronto: Archives \& Museum Informatics, 2005. http://www.archimuse.com/mw2005/papers/diBlas/diBlas.html

[18] SCHARF, G. The Pompeian Court in the Crystal Palace. London, 1854.

[19] SKETCHLEY, A. Mrs Brown at the Crystal Palace. London, 1874.

[20] HALES, S. Recasting antiquity in the Crystal Palace. Arion. 14, 2006, pp.99134.

[21] BLIX, G. From Paris to Pompeii. Pennsylvania, 2008.

[22] PARK, J-C., YANG, J-Y., KIM, H-R., PARK, K-S. and KWON, D-S. A human-robot emotional interaction experiment through an OX quiz game between human and robot. The 3rd International Conference on Ubiquitous Robots and Ambient Intelligence. URAI, 2006.

[23] Learning from online worlds : teaching in Second Life. http://learningfromsocialworlds.wordpress.com

[24] BAYNE, S. Uncanny spaces for higher education : teaching and learning in virtual worlds. Alt-J, Research in Learning Technology, 16.3, September 2008. pp.197-205. 